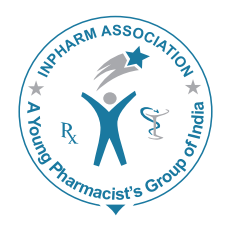

\title{
JYP
}

\section{Formulation and physicochemical evaluation of lozenge tablets containing Salvia officinalis}

\author{
Elmira Bajelan ${ }^{1 *}$, Mohammad Kamali-nejad², Seyed Mohsen Foroutan', \\ Hiam Albasha²
}

${ }^{1}$ Departments of Pharmaceutics, ${ }^{2}$ Pharmacognosy, School of Pharmacy, Shaheed Beheshti University of Medical Sciences, Tehran, Iran

\begin{abstract}
Objective: The aim of this study was to extract the Salvia officinalis leaves, and to formulate the lozenge tablets in order to investigate a profitable dosage form. Methods: Lozenge tablets were prepared using wet granulation. The tablets also were evaluated for the physicochemical properties such as hardness, friability, weigh uniformity, thickness and disintegration time. Results: The selected formulation tablets containing $2.5 \%(\mathrm{w} / \mathrm{w})$ gelatin as a binder and $0.1 \mathrm{ml}$ of Salvia officinalis extract showed their physicochemical properties in the acceptable limits. Furthermore, palatability and the taste of the tablets were found desirable after testing by human volunteers. Salvia officinalis lozenge tablets were studied under accelerated stability conditions, and based on the stability test results it is suggested to package the tablets as single unit dosage form to drug content constancy. Conclusion: The results clearly indicate that the prepared lozenge tablets can be a good alternative for traditional forms of sage.
\end{abstract}

Key words: Salvia officinalis, lozenge, wet granulation, oropharyngeal inflammation, stability

\section{INTRODUCTION}

Pharyngitis or sore thtableoat is an inflammation of the oropharynx, which is one of the most common complaints seen by emergency physicians. ${ }^{1}$ Causes of sore throat include viruses, Streptococcus, mononucleosis, Mycoplasma, gonorrhea, and diphtheria. For a large group of patients, no cause can be established. ${ }^{2}$

\begin{tabular}{|c|l|}
\hline \multicolumn{2}{|c|}{ Access this article online } \\
\hline \multirow{2}{*}{ Journal Sponsor } & $\begin{array}{l}\text { Website: } \\
\text { www.jyoungpharm.org }\end{array}$ \\
\hline \multirow{2}{*}{ www.phcognet } & $\begin{array}{l}\text { DOI: } \\
\text { 10.5530/jyp.2014.1.6 }\end{array}$ \\
\hline
\end{tabular}

A number of drugs are currently considered to be effective for the remission of oral and throat inflammation and infection. ${ }^{3}$ Approximately, one-half of all licensed drugs that were registered worldwide in a 25 -year period prior to 2007 were natural products or their synthetic derivatives. ${ }^{3}$ Herbal medicine, also called botanical medicine or phytomedicine $e^{4}$ are frequently considered to be less toxic and freer from side-effects than the synthetic ones. ${ }^{5}$ For thousands of years, human beings have used and refined herbal extracts for their medicinal effects. The world health organization has estimated that $80 \%$ of the world's population relies solely or largely on traditional remedies for health care and there is speculation that more than 2 billion people may be heavily reliant on medicinal plants. ${ }^{6}$ 
Salvia officinalis L., Lamiacea (common sage) is a perennial woody sub-shrub ${ }^{7}$ native to the northern coastal region of Mediterranean and grows wild in the calcareous mountain of Northern and Central Spain, Southern France, and the Western part of the Balkan Peninsula. ${ }^{8}$ It is used as an herbal medicinal product sold in the form of plant materials for making herbal tea, or as a liquid extract or tincture. $^{9}$

Although well-established traditional uses of sage includes symptomatic treatment of mild dyspeptic complaints, the treatment of inflammation of the mucus membrane of the mouth and throat, and relief of excessive sweating and minor skin inflammations only a few clinical trials thus far have been conducted to corroborate these uses..$^{10}$ For the pharynx anti-inflammatory effect of sage, it administers as chopped drug, alcoholic extracts, and distillates for gargling and rinsing.

Clinical studies of Sage extract suggest that it can be a good candidate to formulate as lozenges for the possible treatment of mouth and sore inflammation. Lozenges are usually sweetened medicated solid dosage forms intended to be held in the mouth containing one or more medicaments. ${ }^{11}$ Lozenges are premeditated to reduce oropharyngeal symptoms and also for systemic effect provided the drugs are well absorbed via the buccal lining or when swallowed. ${ }^{12}$

In this study, for the first time we prepared lozenge dosage form containing $S$. offcinalis essential oil in order to improve both performance and patient tolerance.

\section{MATERIALS AND METHODS}

\section{Plant material}

Leaves of S. officinalis were collected in May 2011 from the collection of medical herbs garden of Shaheed Beheshti University of Medical Sciences (Tehran, Iran) and were dried under the shade at room temperature. Dried leaves were finely chopped and stored in tight dark containers.

\section{Plant extraction}

Dried leaves of $S$. officinalis were submitted to hydrodistillation using a clevenger-type apparatus according to the method recommended in British Pharmacopoeia. The film floating essential oil on the surface of the water was collected stored in a refrigerator at $2-4^{\circ} \mathrm{C}$ until used.

\section{GC-mass analysis}

1,8-cineole as one of the main constituents was analyzed using a Thermo Finnigan gas chromatography-mass spectrophotometer. The essential oil of $S$. officinalis was separated utilizing a RTX ${ }^{\circledR}$ - 5 ms column (15 m length, $0.25 \mathrm{~mm}$ internal diameter, $0.25 \mathrm{~mm}$ df; Bellefonte, PA, USA) running a temperature program (initial temperature $50^{\circ} \mathrm{C}$, $9^{\circ} \mathrm{C} / \mathrm{min}$ to $240^{\circ} \mathrm{C}, 7 \mathrm{~min}$ hold at $240^{\circ} \mathrm{C}$; helium carrier gas at a constant flow rate of $1.2 \mathrm{ml} / \mathrm{min})$. The compounds were detected using Trace GC detector (Thermo Finnigan; ionization energy $70 \mathrm{eV}$, scan frequency range $\mathrm{m} / \mathrm{z} 49-459$ ).

\section{Preparation of S. officinalis lozenge tablets}

The wet granulation technique was adopted to prepare the granules as per formula given in Table 1.

Dry excipients were blended, and the dry mix was moistened with an appropriate amount of $4.7 \%(\mathrm{w} / \mathrm{w})$ microcrystalline cellulose. The wet mass was passed through sieve no.16, and the granules were dried in a hot air oven at $40 \pm 2^{\circ} \mathrm{C}$ for $2 \mathrm{~h}$. The wet granules re-sieved through sieve no.14.

Calculated amount of $S$. officinalis essential oil was mixed with sorbitol and dried in the oven for $1 \mathrm{~min}$ at $40 \pm 2^{\circ} \mathrm{C}$. Afterwards, powder containing essential oil was added to dried granules.

The granules were lubricated with 3\% (w/w) magnesium stearate after that mint extract as a flavoring and propylparaben as a preservative and antibacterial were added.

The formulations were then compressed in a single-punch tableting machine (AR400, Erweka, Germany).

Table 1: Composition of free drug formulations

\begin{tabular}{lccccccccc}
\hline Batch no. & Sorbitol & Avicel & PVP & Gelatin & Propylparaben & Citric acid & Mint extract & Silicon dioxide & Magnesium stearate \\
\hline F1 & 20.73 & 1.22 & - & 0.30 & 0.075 & 0.39 & 1.18 & 0.48 & 0.72 \\
F2 & 20.03 & 1.22 & - & 1.00 & 0.075 & 0.39 & 1.18 & 0.48 & 0.72 \\
F3 & 20.43 & 1.22 & - & 0.60 & 0.075 & 0.39 & 1.18 & 0.48 & 0.72 \\
F4 & 20.73 & 1.22 & - & 0.30 & 0.075 & 0.39 & 1.18 & 0.48 & 0.72 \\
F5 & 20.73 & 1.22 & 0.3 & - & 0.075 & 0.39 & 1.18 & 0.48 & 0.72 \\
F6 & 19.83 & 1.22 & 1.2 & - & 0.075 & 0.39 & 1.18 & 0.48 & 0.72 \\
F7 & 19.83 & 1.22 & 1.2 & - & 0.075 & 0.39 & 1.18 & 0.48 & 0.72 \\
\hline
\end{tabular}

PVP: Polyvinylpyrrolidone 


\section{Physicochemical characterization of tablets}

The prepared tablets were evaluated for organoleptic parameters (color, taste, odor, and touch), hardness, friability, thickness, and weigh uniformity.

The hardness $(n=10)$, friability $(n=10)$ and thickness $(n=10)$ of tablets were calculated using the TBH-28 model hardness tester (Erweka, Germany), the GDAT model of Erweka friabilator (Germany) and the thickness apparatus (Mitutoyo, Japan).

Weigh uniformity was determined by weighing 10 tablets individually, the average weigh was calculated, and the percent variation of each tablet was determined. For estimation of content uniformity, 10 tablets individually were powdered in pestle mortar and dissolved in the mixture of distilled water and chloroform $(1: 2 \mathrm{v} / \mathrm{v})$. Twophase solution was separated by centrifugation at $3500 \mathrm{rpm}$ for $5 \mathrm{~min}$. After chloroform evaporation and dilution by hexane, the 1,8-cineole content in tablets was determined using above-mentioned GC-mass method.

\section{In-vitro disintegration time studies}

Disintegration time was defined as the interval required for complete disappearance of a tablet or its particles from the tester net.

Disintegration test of the prepared tablets was performed according to USP30, using a disintegration tester (Erweka ZT6-1-D, Germany) through the disintegration medium of phosphate buffer with $\mathrm{pH} 6.2$ maintained at $37 \pm 0.5^{\circ} \mathrm{C}$.

\section{Stability test}

For accelerated stability study, selected formulation was kept in airtight dark container according to ICH guidelines at $40 / 75 \%$ relative humidity for 6 months. ${ }^{13}$

\section{Statistical analysis}

All data were expressed as mean \pm standard deviation (SD) of at least three measurements. Statistical calculations were performed using GraphPad PRISM ${ }^{\mathrm{TM}}$ software. Statistical significance between two groups was tested with Student's t-test. Differences among three or more groups were analyzed by the ANOVA test. $P<0.05$ was considered as statistically significant.

\section{RESULTS AND DISCUSSION}

Herbal medicine texts suggest the use of $S$. officinalis for pharyngeal inflammation therapy. In the present work, different formulations of lozenge tablet were prepared using wet granulation and evaluate to obtain optimized formula.

\section{Physicochemical characterization of tablets}

Comparative organoleptic properties of different formula were given in Table 2. F1 and F5 could not pass the test. This seems to be related to the amount of binder and hardness of these batches.

Tablets were also evaluated for hardness, friability, thickness, and weigh uniformity and disintegration time. Results of all parameters are mentioned along with a standard deviation in Table 3.

The standard acceptable range for tablet hardness is 3-40 Kp and all the prepared tablets except F4 passed the following test. The percentage friability in all formulations $\mathrm{F} 1$ to $\mathrm{F} 7$ was found to be $<1 \%$; it suggests good potency of all batches for packaging. ${ }^{14}$ The tablets mean thickness value range from $6.16 \pm 0.13$ to $6.62 \pm 0.12 \mathrm{~mm}$. All the formulae passed the weigh uniformity test. According to the British Pharmacopeia (2004), not more than two of the individual weights should deviate from arrange by more than $5 \%$ and none should deviate by more than twice that percentage. $^{15}$

\section{In-vitro disintegration time}

Table 3 presents the results of disintegration time study of formulated tablets according to composition given in Table 1.

Table 2: Organoleptic properties of drug free lozenge tablets

\begin{tabular}{lcccccc}
\hline $\begin{array}{l}\text { Batch } \\
\text { no. }\end{array}$ & $\begin{array}{c}\text { Surface } \\
\text { smoothness }\end{array}$ & Cracking & Capping & Color & Taste & Odor \\
\hline F1 & - & \pm & - & Off-white & Sweet & Mint \\
F2 & + & - & - & Off-white & Sweet & Mint \\
F3 & + & - & - & Off-white & Sweet & Mint \\
F4 & + & - & - & Off-white & Sweet & Mint \\
F5 & + & \pm & \pm & Off-white & Sweet & Mint \\
F6 & + & - & - & Off-white & Sweet & Mint \\
F7 & + & - & - & Off-white & Sweet & Mint \\
\hline
\end{tabular}

Table 3: Evaluation of drug free lozenge tablets

\begin{tabular}{lccccc}
\hline $\begin{array}{l}\text { Batch Hardness } \\
\text { no. }\end{array}$ & $\begin{array}{c}\text { Friability } \\
(\%)\end{array}$ & $\begin{array}{c}\text { Thickness } \\
(\mathbf{m m})\end{array}$ & $\begin{array}{c}\text { Weigh } \\
\text { uniformity } \\
(\mathbf{m g})\end{array}$ & $\begin{array}{c}\text { Disintegration } \\
\text { time (min) }\end{array}$ \\
\hline F1 & $9.00 \pm 1.8$ & 0.72 & $6.42 \pm 0.12$ & $728.83 \pm 4.40$ & $6.48 \pm 1.33$ \\
F2 & $18.71 \pm 2.98$ & 0.78 & $6.47 \pm 0.09$ & $778.67 \pm 3.30$ & $14.30 \pm 3.83$ \\
F3 & $25.00 \pm 1.87$ & 0.58 & $6.63 \pm 0.13$ & $806.83 \pm 2.70$ & $12.15 \pm 2.89$ \\
F4 & $36.13 \pm 8.09$ & 0.63 & $6.28 \pm 0.15$ & $767.67 \pm 4.20$ & $17.68 \pm 1.06$ \\
F5 & $7.37 \pm 1.54$ & 0.27 & $6.62 \pm 0.12$ & $781.17 \pm 2.20$ & $3.34 \pm 0.88$ \\
F6 & $21.96 \pm 3.80$ & 0.42 & $6.48 \pm 0.09$ & $796.50 \pm 4.60$ & $4.45 \pm 1.81$ \\
F7 & $19.49 \pm 1.43$ & 0.62 & $6.19 \pm 0.11$ & $795.33 \pm 2.80$ & $9.69 \pm 1.37$ \\
\hline
\end{tabular}

Journal of Young Pharmacists Vol 6 • Issue 1 • Jan-Mar 2014 
Not all the lozenge batches were found to disintegrate within the pharmacopoeial limits. The results show that just formulation F2, F3, and F4 passed the test, due to a higher concentration of the binder. These formulations also showed more hardness in comparison to others. Hence, a direct relation between hardness and disintegration time was further confirmed through these results.

\section{Preparation of lozenge tablets containing S. officinalis essential oil}

To the determination of optimized composition for preparing $S$. officinalis lozenge tablets, 7 different formulations were tested.

From the results, F1 which contained $1.25 \%(\mathrm{w} / \mathrm{w})$ gelatin as a binder show inappropriate organoleptic properties, less hardness, and disintegration time compared to others. This could have been caused by the lesser amount of binder. To improve the formulations properties, two methods were studied. First, the amount of gelatin was increased to $4.16 \%$ and $2.5 \%$ in F2 and F3. Although they showed appropriate hardness and disintegration time, F2 created considerable problems during wet granulation. Disintegration time in F3 was significantly increased compared to F1 $(P<0.05)$.

Second, the pressure of tableting machine compression increased to $30 \mathrm{Kp}$, but some tablets of batch F4 including $1.25 \% \mathrm{w} / \mathrm{w}$ gelatin, showed hardness more than standard scale.

On the other hand, PVP as a common binder in the pharmaceutical industry was used for lozenge tablet preparation. None of the F5, F6, F7 containing $0.125 \%$, $0.125 \%$, and $0.5 \%(\mathrm{w} / \mathrm{w})$ PVP passed the physical properties tests, even increasing the pressure of the tableting machine compression in F6 could not change the disintegration time significantly. Therefore, it was established that binder type and its concentration affected the tablet hardness. ${ }^{16}$

Drug loaded tablets prepared according to F3 with an amount of $0.1 \mathrm{ml}$ of $S$. officinalis essential oil and evaluate for organoleptic properties, hardness, friability, thickness, weigh uniformity, and disintegration time, etc. (Tables 4 and 5).

It can be observed from the results that the prepared formulation passes the test according to pharmacopeia. The content uniformity among different tablets was discovered to be desirable and was found to be more than $96 \%$.

\section{Stability test of tablets}

The results of stability study during 6 months were shown in Table 6. During the accelerated stability study tablets were characterized for hardness, friability, weigh uniformity, disintegration time, and drug content. The results indicated no significant difference in physical properties, but the drug content decrease significantly $(P<0.05)$, which was caused by evaporation of volatile oil presenting in the tablets into container area. Although, the results suggests the $S$. officinalis lozenge tablets must be packaged as a single unit dosage forms.

\section{CONCLUSION}

The present study was carried out in order to develop lozenge tablet of $S$. officinalis for the treatment of pharyngeal inflammations. After wet granulation, the optimized formula was prepared by direct compression and exhibited optimum hardness, friability, and weigh uniformity and disintegration time. Future work will be needed to evaluate the effect of tablet coating on stability, and also clinical trials can reconfirm the $S$. officinalis efficacy as lozenge form for treatment of patient with oropharyngeal inflammations.

\section{ACKNOWLEDGMENT}

The authors would like to thank the financial support offered by research deputy of Shaheed Behehsti University of Medical Sciences.

Table 4: Organoleptic properties of Salvia officinalis lozenge tablets

\begin{tabular}{lcccccc}
\hline $\begin{array}{l}\text { Batch } \\
\text { no. }\end{array}$ & $\begin{array}{c}\text { Surface } \\
\text { smoothness }\end{array}$ & Cracking & Capping & Color & Taste & Odor \\
\hline F8 & + & - & - & Off-white & Sweet & Mint \\
\hline
\end{tabular}

Table 5: Evaluation of Salvia officinalis lozenge tablets

\begin{tabular}{llllll}
\hline $\begin{array}{l}\text { Batch Hardness } \\
\text { no. }\end{array}$ & $\begin{array}{c}\text { Friability } \\
(\%)\end{array}$ & $\begin{array}{c}\text { Thickness } \\
(\mathbf{m m})\end{array}$ & $\begin{array}{c}\text { Weigh } \\
\text { uniformity } \\
(\mathbf{m g})\end{array}$ & $\begin{array}{c}\text { Disintegration } \\
\text { time (min) }\end{array}$ \\
\hline F8 & $26.80 \pm 4.80$ & 0.51 & $6.56 \pm 0.32$ & $805.00 \pm 2.43$ & $11.02 \pm 1.11$ \\
\hline
\end{tabular}

Table 6: Stability study of Salvia officinalis lozenge tablets

\begin{tabular}{lccccc}
\hline $\begin{array}{l}\text { Time } \\
\text { (month) }\end{array}$ & $\begin{array}{c}\text { Hardness Friability } \\
\text { (Kp) }\end{array}$ & $\begin{array}{c}\text { Weigh } \\
\text { uniformity } \\
\text { (mg) }\end{array}$ & $\begin{array}{c}\text { Disintegration } \\
\text { time (min) }\end{array}$ & $\begin{array}{c}\text { Drug } \\
\text { content (\%) }\end{array}$ \\
\hline 0 & $29.80 \pm 4.80$ & 0.48 & $805.00 \pm 2.43$ & $11.02 \pm 1.11$ & 100 \\
2 & $27.19 \pm 3.98$ & 0.19 & $782.50 \pm 1.42$ & $11.08 \pm 3.02$ & 74.32 \\
4 & $27.49 \pm 4.04$ & 0.19 & $773.67 \pm 2.56$ & $11.50 \pm 2.64$ & 65.86 \\
6 & $30.05 \pm 1.60$ & 0.18 & $773.33 \pm 4.43$ & $10.10 \pm 4.43$ & 58.57 \\
\hline
\end{tabular}




\section{REFERENCES}

1. Renner B, Mueller CA, Shephard A. Environmental and non-infectious factors in the aetiology of pharyngitis (sore throat). Inflamm Res 2012;61:1041-52.

2. Wannamaker LW. Perplexity and precision in the diagnosis of streptococcal pharyngitis. Am J Dis Child 1972;124:352-8.

3. Schapowal A, Berger D, Klein P, Suter A. Echinacea/sage or chlorhexidine/ lidocaine for treating acute sore throats: A randomized double-blind trial. Eur J Med Res 2009;14:406-12.

4. Hawkins EB, Ehrlich SD. Herbal medicine: Overview, 2007. Available from: http://www.umm.edu/altmed/articles/herbal-medicine-000351.htm. [Last accessed on: 2014 May 03].

5. Momin A. Role of indigenous medicine in primary health care. $1^{\text {st }}$ International Seminar on Unani Medicine, New Delhi, India; 1987. p. $54-5$.

6. Smith-Hall C, Larsen HO, Pouliot M. People, plants and health: A conceptual framework for assessing changes in medicinal plant consumption. J Ethnobiol Ethnomed 2012;8:43.

7. Domaracký M, Rehák P, Juhás S, Koppel J. Effects of selected plant essential oils on the growth and development of mouse preimplantation embryos in vivo. Physiol Res 2007;56:97-104.

8. Radosavljević I, Jakse J, Javornik B, Satovic Z, Liber Z. New microsatellite markers for Salvia officinalis (Lamiaceae) and cross-amplification in closely related species. Am J Bot 2011;98:e316-8.

9. Walch SG, Kuballa T, Stühlinger W, Lachenmeier DW. Determination of the biologically active flavour substances thujone and camphor in foods and medicines containing sage (Salvia officinalis L.). Chem Cent J 2011;5:44.

10. Walch SG, Tinzoh LN, Zimmermann BF, Stühlinger W, Lachenmeier DW Antioxidant capacity and polyphenolic composition as quality indicators for aqueous infusions of Salvia officinalis L. (sage tea). Front Pharmacol 2011;2:79.

11. Sastry SV, Nyshadham JR, Fix JA. Recent technological advances in oral drug delivery - a review. Pharm Sci Technolo Today 2000;3:138-45.

12. Waugh A, Grant A. Disease of the mouth. Ross and Wilson Anatomy and Physiology in Health and Illness. $9^{\text {th }}$ ed. Edinburgh: Churchill Livingstone; 2001. p. 319.

13. Sane RT. Standardization, quality control and GMP's for herbal drugs. IDMA Bull 2002;33:162-8.

14. Pandya VP, Patel VB, Patel P. Formulation, evaluation and optimization of sustained release matrix tablets of captopril. J Pharm Bioallied Sci 2012;4 Suppl 1:S77-8.

15. Esimone $\mathrm{CO}$, Onuh PU, Egege MK, Ugoeze KC, Obitte NC. In vitro evaluation of lozenges containing extracts of roots of Zapoteca portoricensis (FAM: Fabaceae). J Pharmacol Toxicol 2009;4:132-7.

16. Reading SJ, Spring MS. The effects of binder film characteristics on granule and tablet properties. J Pharm Pharmacol 1984;36:421-6. 